\title{
Reflections on embedding safety throughout the process engineering program
}

\author{
Michaela Pollock, Eva Sorensen ${ }^{1}$ \\ Department of Chemical Engineering,UCL, Torrington Place, London, WC1E \\ 7JE, United Kingdom \\ le.sorensen@ucl.ac.uk
}

\begin{abstract}
Safety is an important part of being a well-rounded, responsible process engineer. It not only covers fundamental scientific knowledge but also a way of thinking and culture in how engineers approach their work, and is continually developed throughout the working life of a process engineer. However, how this safety learning can start to be imparted to engineering students in an academic environment is a challenge for educators. In this work the systems approach that has been taken as part of UCL's Integrated Engineering Program (IEP) teaching framework is examined. Within this framework, safety is embedded into the curriculum from the start in Year 1 and is continually extended and advanced throughout the process engineering program. As the first cohort of students graduate we reflect on how this has been implemented and received.
\end{abstract}

Keywords: teaching, safety, embedded learning

\section{Introduction}

The significance of safety within process engineering is widely acknowledged in industry and education. However, the learning, and application of that learning, in an industrial and educational context is very different. In an industrial setting, where recent engineering graduates are applying their newly-gained fundamental knowledge to reallife problems within interdisciplinary teams of varying experience, it is easy to comprehend how the graduates can build on their fundamental knowledge to develop into well-rounded, safety-aware and responsible engineers. These real-life settings and awareness of the full context of safety, are challenging for educators to impart to students who are still developing their knowledge of core chemical engineering subjects and have limited if any industrial experience.

Ultimately, these challenges cannot be overlooked by educators aiming to prepare a young person for a career in engineering, as imparting an understanding and awareness of safety is a key learning outcome required by accreditation bodies globally. The IChemE's accreditation guidelines (IChemE, 2017) require graduating students to have gained an understanding of a variety of process safety learning outcomes, such as inherent safety, principles of risk assessment and methods of identifying process hazards. In addition to formally taught safety courses, the IChemE insists that students are instilled with appropriate attitudes to safety, health \& the environment (SH\&E). Similarly, the ABET criteria for chemical engineering programs (ABET, 2017) state that the curriculum must include the hazards associated with chemical, physical and/or biological processes. These open-ended and wide-ranging learning outcomes on safety 
are mirrored in numerous fundamental process safety textbooks, such as Crowl \& Louvar (2011), who propose that successful safety programs require several elements including fundamentals, experience and attitude.

The Department of Chemical Engineering at UCL offers both Bachelor and Masters programs in Chemical Engineering through its Integrated Engineering Programme (IEP) (Sorensen, 2016), with around 120-150 students per cohort. The IEP is a Faculty-wide, multidisciplinary program which started in 2014/15 and combines core disciplinary technical knowledge with interdisciplinary and/or research-based projects with strong emphasis on professional skills and academic learning connected with workplace learning. The program enables students to understand the fundamentals of their discipline, to practice the application of their core technical knowledge and to apply this to current complex global challenges such as energy, health etc. Students also have the opportunity to apply their fundamental learnings to industrially-relevant mini-design projects, known as scenarios. This focus on problem and/or project-based learning starts in Year 1 and continues throughout the program. As for most UK programs, most courses are compulsory in Years 1-3, and are taken by the entire cohort at the same time. It is therefore possible to properly plan the delivery of key concepts such as safety to ensure the material is introduced at the right time and that there is a clear progression from one course to the next or from one year to the next.

The IEP framework enables a systems approach to teaching safety to be undertaken. Firstly, from a depth perspective where safety is embedded into the curriculum immediately in Year 1 and the level of understanding is built upon in subsequent years. Secondly, from a breadth perspective, where different safety learnings are applied to an assortment of industrially-relevant problems throughout the program.

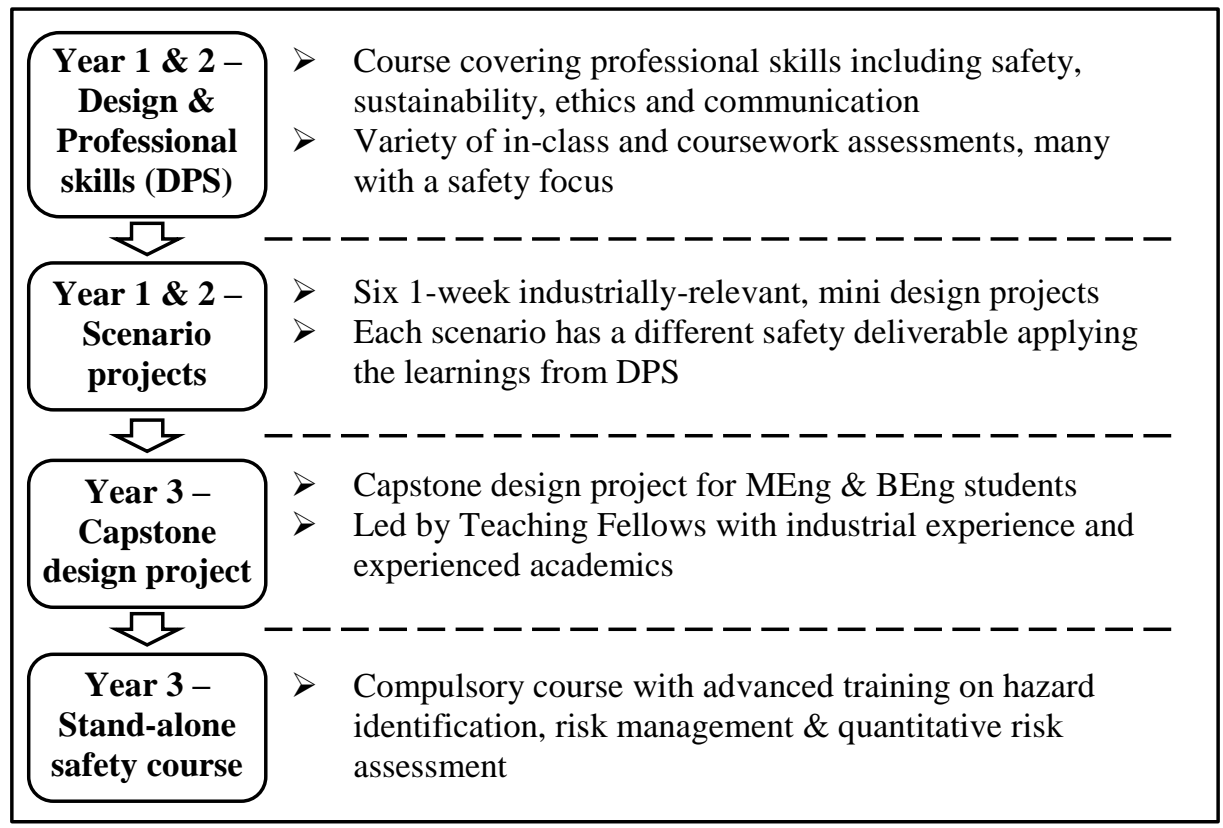

Figure 1: Illustration of how safety is embedded in the UCL Integrated Engineering Program (IEP) teaching framework. 
Figure 1 illustrates how safety has been embedded throughout the IEP framework. In the remainder of this paper, the methods used to introduce and apply safety concepts in Years 1 and 2 are examined, and the approaches taken to extend this to advanced application and learning in Year 3 are then outlined. As the first cohort of students graduate from the IEP framework, reflections on embedding safety teaching and student feedback are examined, followed by conclusions on the approach.

\section{Introducing safety concepts in Years 1 and 2}

As soon as students arrive on campus they are introduced to the concepts associated with safety as one element of the 'Design and Professional Skills' course. Topics covered include risk, hazards, inherent safety and hazard evaluation techniques. Initially these concepts are introduced in Year 1 by considering everyday situations to which students can easily relate. For example, examining a photo of a staircase and considering safety strategies that can be adopted, or performing a HAZID (hazard identification) on everyday activities such as the commute of a cyclist in London. In Year 1, this is also extended to the context of the process industries through lecture examples which briefly introduce past accidents and utilise simple process examples such as an example of a HAZOP (hazard and operability study) on a fired heater. As in Shallcross (2013), assessment is introduced in terms of examining past accidents and considering issues that led to, and lessons learned from, the incident.

As students proceed through the second year of the IEP program, safety concepts and hazard evaluation techniques continue to be examined with a greater emphasis on process industries and their application to different stages in the process design timeline. As suggested by Shallcross (2014), brief 5 minute safety shares, which reflect industrial practice of focusing safety discussions at the start of meetings, are used to introduce safety topics covered in the lectures. Topics examined range from dangers in the home, major process incidents such as Bhopal and lessons learned from other industries such as the sinking of the Herald of Free Enterprise.

Supporting material for lecture content comes from traditional textbooks such as AIChE CCPS (2008) and Mannan \& Lees (2012). This is supplemented by safety videos from the IChemE Safety Centre (ISC) (Kerin, 2016) and the Chemical Safety Board (CSB) (Horowitz and Gilmour, 2007) to highlight particular topics covered within lectures and to illustrate the context of process industries to students who potentially have not yet set foot on a process plant. One particular topic covered in the second year is hazards and control of exothermic reactions, fulfilling the recommendations from the CSB following the T2 Laboratories accident that awareness of reactive hazards is incorporated into the curriculum (Crowl \& Louvar, 2011).

\section{Applying safety learnings in Years 1 and 2}

Ultimately, the subjects of engineering and safety are applied subjects. As such, students on the IEP program are given the opportunity to apply their safety learnings through a safety deliverable incorporated into each of the six industrially-relevant, week-long mini design projects, known as scenarios, which are completed in the first two years of the IEP degree program. As an example, in a scenario on air separation for the production of nitrogen for food packaging, students produced a safety newsletter 
examining a past accident involving cryogenic distillation and reported findings from a HAZID performed on their nitrogen production plant. The form of the deliverable, a safety newsletter, replicated a common industrial safety document. In addition, this scenario increased students' awareness of technical documentation and standards through the freely available publications of the European Industrial Gases Association (EIGA) accessed via EIGA (2017).

The variety and format of the six scenarios completed during the first two years allows students to apply safety learnings on processes with which they are already familiar. This is representative of experiences of process engineers in industry where engineers perform hazard evaluations on processes well known to them as well as to unfamiliar processes. For example, in a Year 1 scenario, students performed a HAZOP on a reactor involved in styrene monomer production based on a process flow diagram (PFD) which they constructed from a process description provided in the student brief. In Year 2, the design of the styrene monomer process was further developed into a detailed PFD with some initial control strategies by teaching staff. The students were again asked to perform a HAZOP, this time on a distillation column and surrounding secondary units. By embedding safety into the curriculum, students are able to perform hazard evaluations on a process they have already encountered and on engineering documentation with varying levels of detail reflecting different stages in the process design timeline. Furthermore, students learn about fundamental chemical processes, such as distillation and reactors, and concurrently consider safety issues related to the design and operation of these units.

\section{Advancing safety learning in Year 3}

The safety learnings are further embedded in the third year in two parallel approaches, the capstone design project and a stand-alone Advanced Safety and Loss Prevention course. These courses, and their scheduling together, encourages in-depth learning of safety concepts through advanced application of hazard evaluation methods and deeper learning of the consequences of hazards, their quantification and safety management systems.

The capstone design project, which accounts for a quarter of the third year and where students work in teams of 6-7 students, is arranged in a manner so that students follow the development of a process from research and conceptual design, through preliminary, and then detailed design. As discussed in Towler \& Sinnott (2012), the engineering information available, and the hazard evaluation methods that can be employed to assess the hazards related to the process, differ at every stage of the project. This is one of the key learnings for students where at every stage of the design project a different hazard evaluation, or safety element, is performed.

During the initial research and conceptual design stage, students investigate what is known to them in the form of a safety data sheet (SDS) review and are recommended to review literature on past accidents for similar processes. They then use this knowledge to perform a preliminary hazard analysis (PreHA) of the conceptual design in their design teams, focusing on potential hazards related to feedstock, major units, utility and support systems and other categories as relevant to the chosen project. This approach is flexible and allows students to focus on areas relevant to their process, for example, 
major units such as exothermic reactors in vinyl chloride monomer production or storage of feedstock in the conversion of biomass into bioethanol.

The design project then moves into preliminary design as students develop their process further with a detailed PFD and process simulation. At this stage, following formative and summative feedback on their PreHA study and their second year HAZOP workshop, students perform a HAZOP on the process they are developing. Knowledge from the chemical review and any review of past accidents again aid in the hazard evaluation of the process and recommendations from the HAZOP often give an indication of potential control system requirements.

Students then move onto the individual component of the capstone design project where they are required to develop a detailed design of a major process unit, typically a separation unit, such as a distillation or absorption column, or a reactor unit. As they take their individual unit design through the process design stage and into detailed design, students develop a control system for their unit which they then represent on a piping and instrumentation diagram (P\&ID). To complete the detailed design stage, students perform a safety integrity level (SIL) analysis where they quantitatively assess the reliability of their system. They identify the major hazards associated with their unit by looking back over findings from the PreHA, HAZOP and past accident reviews. For the selected major hazard they then identify a tolerable risk threshold for the hazard. To evaluate the reliability of their individual process unit design, students then develop a Fault Tree to identify the causes that can lead to the hazard and quantify the risk of the hazard occurring. Following comparison with the tolerable risk threshold, students then formulate recommendations of further actions, if any, required for the process design.

The safety teaching within the IEP framework concludes with a compulsory stand-alone Advanced Safety and Loss Prevention course extending the students' existing knowledge and awareness of safety. The course has a strong focus on risk management, management systems and quantitative risk assessment. The causes and physical effects of hazards are examined in detail and the course concludes by examining the concepts of reliability and availability. Assessment is split between $80 \%$ exam-based and $20 \%$ coursework-based.

\section{Reflections on embedding safety within the IEP framework}

At the end of 2016/17, as the first cohort of students were about to graduate with a Bachelor's in chemical engineering following the IEP framework, the students were asked for feedback on their perceptions of the IEP approach to embedding safety learning. Over $90 \%$ of the respondents Somewhat or Strongly agreed with the statements that they understood the importance of safety in society in general, in chemical engineering and the concepts of inherent safety. When asked in which year they had been first introduced to the concepts of risk, hazard and accidents or had the opportunity to apply their safety knowledge, over $50 \%$ of respondents indicated in their first year. While this does indicate that some further emphasis of safety teaching and its application is still needed in the first year, we can see that we are well on our way to achieving our goals of developing graduate engineers well prepared for a career in engineering with one student commenting "courses are taught with a safety aspect in mind so that safety becomes part of our everyday critical thinking”. 


\section{Conclusions}

In conclusion, embedding safety throughout the process engineering curriculum has been successfully achieved using a systems approach at UCL Engineering as part of the Integrated Engineering Program (IEP) teaching framework. This has been validated through the successful accreditation of the UCL IEP chemical engineering degree by the IChemE in 2016. Furthermore, student feedback has indicated significant understanding of the importance of safety in chemical engineering and in society in general. Finally, it is important to emphasise that such an all-encompassing program can only be achieved through the efforts of staff, many of whom are chartered engineers, with a wide range of academic, industrial and lab experience which mirrors the wide-ranging background and experience of engineers that graduates will work with in future roles.

\section{References}

ABET, 2017, Criteria for accrediting engineering programs, http://www.abet.org/wpcontent/uploads/2017/12/E001-18-19-EAC-Criteria-11-29-17-FINAL.pdf [accessed 2 December 2017].

AIChE Center for Chemical Process Safety (CCPS), 2008, Guidelines for hazard evaluation procedures, CCPS, New York, N. Y., Wiley-Interscience, Hoboken, N. J.

D. A. Crowl and J. F. Louvar, 2011, Chemical Process Safety Fundamentals with Applications, Prentice Hall, Upper Saddle Hall, N. J., $3^{\text {rd }}$ Ed.

European Industrial Gases Association (EIGA), 2017, Catalogue of EIGA publications, https://www.eiga.eu/index.php?eID=dumpFile \&t=f\&f=149\&token=3af8d1141e323b0294428 1b731348c5fa28071da [accessed 1 December 2017].

D. M. Horowitz and S. Gilmour, 2007, CSB Safety Videos: A new and effective communication tool for accident investigation findings, Process Safety Progress, 26, 3, 177-179.

IChemE, 2017, Accreditation of chemical engineering programmes A guide for higher education providers and assessors, http://icheme.org/accreditation/university-accreditation/guidance.aspx [accessed 2 December 2017].

T. Kerin, 2016, A new way of learning from incidents - ISC's new case-study based training eliminates hindsight bias, The Chemical Engineer, 900, 51.

S. Mannan and F. P. Lees, 2012, Lee's loss prevention in the process indusstries: hazard identification, assessment, and control, Butterworth-Heinemann, Boston, Elsevier, Amsterdam.

D. C. Shallcross, 2013, Safety education through case study presentations, Education for Chemical Engineers, 8, e12-e20.

D. C. Shallcross, 2014, Safety shares in the chemical engineering class room, Education for Chemical Engineers, 9, e94-e105.

E. Sorensen, 2016, Changing the World - Educating students differently with a more scenario and problem-based engineering curriculum, The Chemical Engineer, 904, 27-30.

G. Towler and R. K. Sinnott, 2012, Safety and Loss Prevention in Chemical Engineering Design: Principles, Practice and Economics of Plant and Process Design, Elsevier Science, Amsterdam, $2^{\text {nd }} \mathrm{Ed}$. 